\title{
The effect of footwear on multi-segment foot kinematics during running
}

\author{
Robin L Bauer,, Mukta N Joshi, Trevor R Klinkner, Stephen C Cobb \\ From 3rd Congress of the International Foot and Ankle Biomechanics Community \\ Sydney, Australia. 11-13 April 2012
}

\section{Background}

Footwear is intended to prevent lower extremity injuries caused by excessive foot-ground impacts and faulty mechanics. However, no clear relationship between shoe habits and injury risk has been established [1]. Many studies have examined barefoot versus shod running kinematics, but the results have been equivocal $[2,3]$. A factor in the inconsistent results could be the relationship between foot structure and function. For example, Cobb et al. demonstrated significant walking gait kinematic differences between participants with typical and low arch foot structures using a multi-segment foot model [4]. The purpose of this study was to investigate effects of footwear on multi-segment foot kinematics during running in participants with low arch structure.

\section{Materials and methods}

Five healthy participants $(26.8 \pm 9.01$ yrs; $171.5 \pm 9.85$ $\mathrm{cm} ; 71.61 \pm 15.46 \mathrm{~kg}$ ) with low arch structure completed 10 running trials at $4.0( \pm 10 \%) \mathrm{m} / \mathrm{s}$ in flat sandal and barefoot conditions. Marker clusters placed on the skin or custom-built wands identified six functional articulations: rearfoot complex (RC), calcaneonavicular complex (CNC), calcaneocuboid joint (CC), medial forefoot (MFF), lateral forefoot (LFF), and 1st metatarsophalangeal complex (MTP). Repeated measures MANOVAs $(\alpha$ $\leq 0.05$ ) were used to analyze within-subject sagittal, frontal and transverse plane range of motion (ROM) and initial contact position differences between footwear conditions for the $\mathrm{RC}, \mathrm{CNC}$, and $\mathrm{CC}$ articulations. Dependent t-tests $(\alpha \leq 0.05)$ were performed to assess MTP, MFF and LFF articulation sagittal plane ROM differences between the footwear conditions.

\section{Results}

ROM between conditions are shown in Table 1 and initial contact positions are shown in Table 2.

\section{Conclusions}

Runners alter their gait from shod to barefoot running. The ROM differences suggest runners adapt by increasing motion during stance phase. Initial contact positions

Table 1 ROM mean \pm SD results for Sagittal, Frontal and Transverse planes of motion

\begin{tabular}{|c|c|c|c|c|c|c|}
\hline & \multicolumn{3}{|c|}{ Barefoot } & \multicolumn{3}{|c|}{ Flat } \\
\hline & Sagittal Plane & Frontal Plane & Transverse Plane & Sagittal Plane & Frontal Plane & Transverse Plane \\
\hline $\mathrm{RC}$ & $22.16 \pm 3.18$ & $8.33 \pm 1.72$ & $16.99 \pm 1.92$ & $20.44 \pm 5.30$ & $8.10 \pm 2.92$ & $13.98 \pm 2.95$ \\
\hline CNC & $10.85 \pm 2.57$ & $8.11 \pm 2.67$ & $6.35 \pm 1.72$ & $9.39 \pm 4.02$ & $6.14 \pm 4.33$ & $7.44 \pm 2.35$ \\
\hline $\mathrm{CC}$ & $18.66 \pm 1.86$ & $9.69 \pm 2.44$ & $8.88 \pm 2.92$ & $14.48 \pm 5.35$ & $7.02 \pm 2.75$ & $7.45 \pm 1.45$ \\
\hline MFF & $20.90 \pm 4.68$ & & $20.14 \pm 3.60$ & & & \\
\hline MTP & $41.35 \pm 5.39^{*}$ & & $33.33 \pm 1.76^{*}$ & & & \\
\hline LFF & $7.68 \pm 3.19$ & & $9.34 \pm 2.52$ & & & \\
\hline
\end{tabular}

*indicates a significant difference $(p<0.05)$ between footwear conditions.

\footnotetext{
* Correspondence: rlbauer@uwm.edu

Department of Kinesiology, University of Wisconsin-Milwaukee, Milwaukee,

WI 53201, USA
}

\section{() Biomed Central}

(c) 2012 Bauer et al; licensee BioMed Central Ltd. This is an Open Access article distributed under the terms of the Creative Commons Attribution License (http://creativecommons.org/licenses/by/2.0), which permits unrestricted use, distribution, and reproduction in any medium, provided the original work is properly cited. 
Table 2 Significant initial contact positions $(p<0.05)$ mean \pm SD results between footwear conditions.

\begin{tabular}{lcccccc}
\hline & \multicolumn{3}{c}{ Barefoot } & & \multicolumn{2}{c}{ Flat } \\
\cline { 2 - 7 } & Sagittal Plane & Frontal Plane & Transverse Plane & Sagittal Plane & Frontal Plane & Transverse Plane \\
\hline CNC & $2.81 \pm 4.17$ & $.38 \pm 2.52$ & $-1.53 \pm 3.03^{*}$ & $1.51 \pm 2.67$ & $.07 \pm 5.22$ & $-4.34 \pm 3.38^{*}$ \\
\cline { 1 - 2 } & $5.46 \pm 7.60$ & $-2.08 \pm 2.84$ & $-3.37 \pm 3.23^{*}$ & $3.08 \pm 4.03$ & $2.60 \pm 4.26$ & $2.50 \pm 1.97^{*}$ \\
\cline { 1 - 1 } & $-14.12 \pm 10.38^{*}$ & & $-2.54 \pm 7.63^{*}$ & & & \\
\hline
\end{tabular}

*indicates a significant difference $(\mathrm{p}<0.05)$ between footwear conditions.

demonstrate differences in strike pattern. Higher sagittal plane values for barefoot trials may indicate more midfoot/forefoot landing. These data may enhance the understanding of shoe-wear and running-related injuries.

\section{Acknowledgements}

This study was supported by a grant from the UW-Milwaukee Graduate School.

Published: 10 April 2012

\section{References}

1. Wen D: Risk factors for overuse injuries in runners. Curr Sports Med Rep 2007, 6:307-313.

2. De Wit $B$, Clercq $D$, Aerts P: Biomechanical analysis of the stance phase during barefoot and shod running. J Biomech 2000, 33:269-278.

3. Lieberman D, Venkadesan M, Werbel W, Daoud A, Andrea S, Davis I, Mang'Eni R, Pitsiladis Y: Foot strike patterns and collision forces in habitually barefoot versus shod runners. Nature 2010, 463:531-535.

4. Cobb S, Tis L, Johnson J, Wang Y, Geil M, McCarty F: The effect of lowmobile foot posture on multi-segment medial foot model gait kinematics. Gait Posture 2009, 30:334-339. foot kinematics during running. Journal of Foot and Ankle Research 2012 5(Suppl 1):O2.

\section{Submit your next manuscript to BioMed Central} and take full advantage of:

- Convenient online submission

- Thorough peer review

- No space constraints or color figure charges

- Immediate publication on acceptance

- Inclusion in PubMed, CAS, Scopus and Google Scholar

- Research which is freely available for redistribution

Submit your manuscript at www.biomedcentral.com/submit 